\title{
Phenotypical heterogeneity of mitochondrial encephalopathy with lactic acidosis and stroke-like episodes in a patient with recurrent movement disorder
}

\author{
Hyug-Gi Kim, Kyung Mi Lee^ \\ Department of Radiology, Kyung Hee University Hospital, Kyung Hee University College of Medicine, Seoul, Republic of Korea \\ Correspondence to: Kyung Mi Lee, MD, PhD. Department of Radiology, Kyung Hee University Hospital, Kyung Hee University College of Medicine, \\ Seoul 02447, Republic of Korea. Email: bandilee@khu.ac.kr.
}

Submitted Aug 13, 2021. Accepted for publication Oct 18, 2021.

doi: 10.21037/qims-21-802

View this article at: https://dx.doi.org/10.21037/qims-21-802

A 51-year-old woman with a history of left-arm tremor at rest for 8 months, dysarthria, and hearing loss was hospitalized with generalized edema. She had been diagnosed with diabetes mellitus (DM) 19 years earlier. Her mother and little sister died of DM at the ages of 55 and 33. Her first sister committed suicide, and second sister did not have health problems. At the time of admission, her blood pressure was $117 / 81 \mathrm{mmHg}$, heart rate was 90 beats per min, and body temperature was $37.3{ }^{\circ} \mathrm{C}$. On physical examination, the patient was very skinny with a height of $150 \mathrm{~cm}$, weight of $26 \mathrm{~kg}$, and body mass index (BMI) of $11.55 \mathrm{~kg} / \mathrm{m}^{2}$. On electromyography examination, it showed that the patient had sensorimotor polyneuropathy, such as the demyelinating type. Motor examination revealed slightly decreased muscle strength and tone. The other systemic and neurological examination with mental status results were normal. There was no evidence of seizure like motion or cognitive impairment. Brain magnetic resonance imaging (MRI) was done for further evaluation of motion disorder and revealed bilateral symmetric calcifications in both basal ganglia (BG) and ventral thalami. The lesions in the caudate nucleus and putamen had high signal intensity (SI) and the lesions in the globus pallidus had low SI on T1weighted images; the lesions were dark SI on T2-weighted images, there were blooming artifacts on susceptibilityweighted imaging (Figure 1A-1C). Furthermore, the volume of the putamen was slightly decreased, and the volumes of both cerebellum were markedly decreased (Figure 1D). Deep gray matter (GM) calcifications were confirmed on computed tomography (Figure 1E,1F). Blood examination revealed lactic acidemia (level was $4.13 \mathrm{mmol} / \mathrm{L}$, normal range $<2 \mathrm{mmol} / \mathrm{L}$ ). Thyroid and parathyroid hormone concentrations and serum calcification were normal. For evaluation of the unusual family history of hyperglycemia, the gene study was done. The MT-LT1 mitochondrial $3243 \mathrm{~A}>\mathrm{G}$ pathogenic variation was positive (heteroplasmy $20-27 \%)$. Based on the family history, laboratory and imaging findings, the patient was diagnosed with unusual mitochondrial encephalopathy with lactic acidosis and stroke-like episodes (MELAS) without a stroke episode. All procedures performed in studies involving human participants were in accordance with the ethical standards of the institutional and/or national research committee(s) and with the Helsinki Declaration (as revised in 2013). Written informed consent was obtained from the patient for publication of this case report and accompanying images. A copy of the written consent is available for review by the editorial office of this journal.

\section{Discussion}

Mitochondrial encephalomyopathies can be divided into

^ ORCID: 0000-0003-3424-0208. 

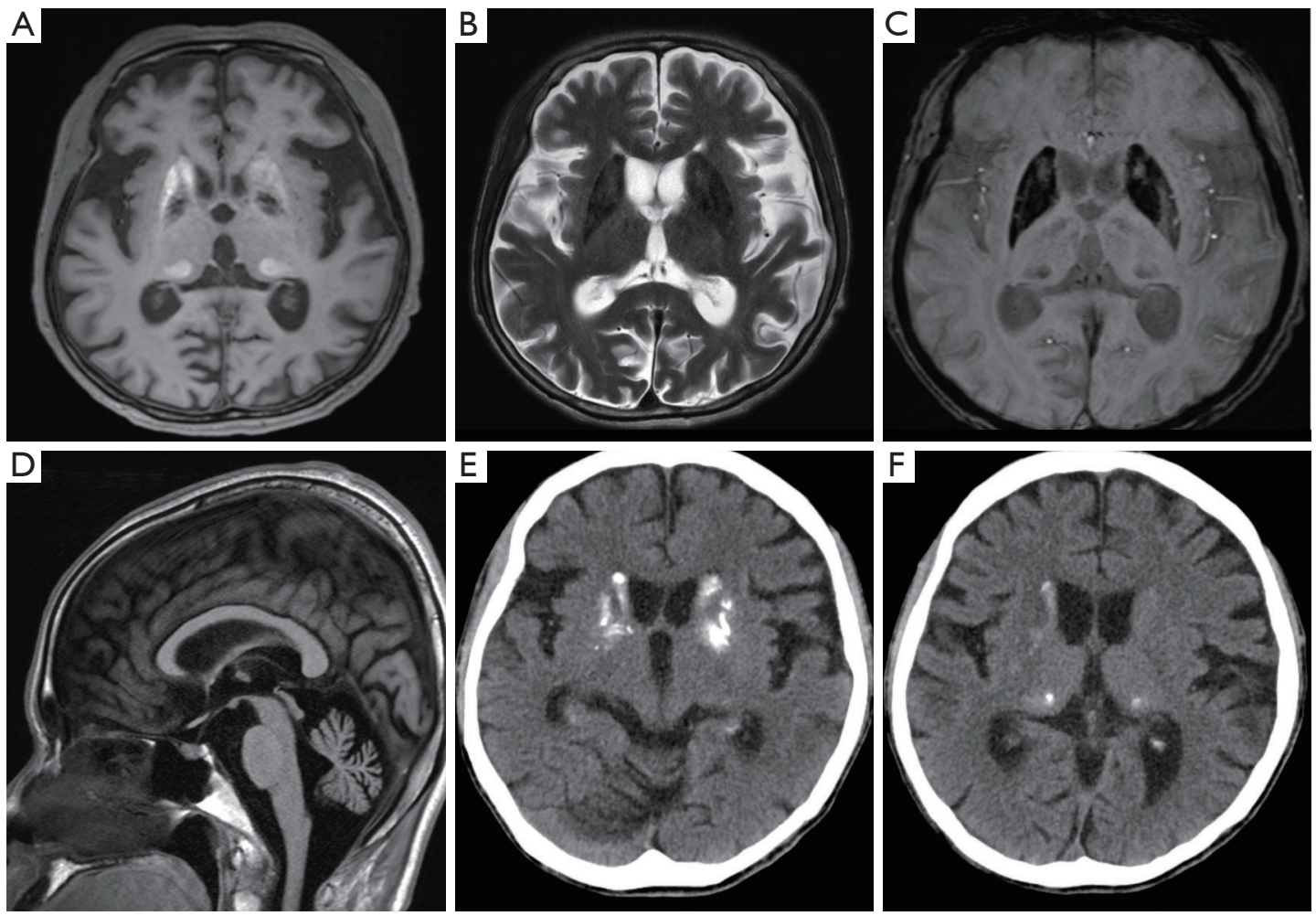

Figure 1 Imaging findings of intracranial calcifications. (A) Axial T1WI showed high SI in the bilateral caudate nucleus-putamen and ventral thalamus and low SI in the globus pallidus. There were corresponding low SI on (B) T2WI and (C) SWI sequences. (D) Sagittal T1WI showed cerebellar atrophy. (E,F) Follow-up CT scan revealed bilateral calcifications at deep GM. T1WI, T1-weighted imaging; SI, signal intensity; T2WI, T2-weighted imaging; SWI, susceptibility weighted imaging; CT, computed tomography; GM, gray matter.

three main syndromes (1): MELAS, myoclonus epilepsy associated with ragged red fibers (MERRF) and KearnsSayre syndrome (onset before age 20, retinitis pigmentosa and ophthalmoplegia). The clinical, biological, radiological, and hematologic findings of our patient correspond to MELAS except a stroke episode. The mitochondrial $3243 \mathrm{~A}>\mathrm{G}$ mutation has been described as a major cause of MELAS. This mutation was reported to reduce tRNA (Leu(UUR)) aminoacylation and the modification of its anticodon wobble position, which results in defective mitochondrial protein synthesis (2). Symptoms such as stroke-like episodes or seizure-like motion disorders begin between 3 and 35 years of age (1). Antecedents suggest a characteristic maternal transmission of mitochondrial disease linked to mutations in mitochondrial DNA.

Parenchymal brain lesions are not categorized based on arterial territory, which is classic in MELAS (1). They can be explained by four pathophysiological mechanisms (3): first, ischemic angiopathy due to the accumulation of abnormal mitochondria in endothelial cells and the smooth muscle of intracranial vessels; second, a cardioembolic cause, obstruction of the large arteries, and tissue anoxia due to mitochondrial dysfunction; third, through the role played by mitochondria in the regulation of intracellular calcium concentrations, these calcifications may be due to hereditary causes or abnormalities in phosphocalcic metabolism as in hypoparathyroidism (4). Our patients showed bilateral calcifications in the deep GM and cerebellar atrophy, but there was no evidence of infarction. Calcifications of the BG were observed in $54 \%$ of the cases, but they rarely affected the cerebellum. Prominent calcifications can be observed in both young and old patients (age range, 17-76 years) (4). Sue et al. (4) reported that deep GM calcifications were not observed during the initial workup of MELAS patients (4 patients), but they were detected by the follow-up MRI taken 4-5 years late. They also reported 
that the calcifications were symmetric, progressive, most commonly involved the globus pallidus, and were not observed in the dentate nucleus (4).

Fahr disease and hypoparathyroidism are important and frequent causes of BG calcification and may occur in association with mitochondrial diseases (5). Deep GM calcifications in our patient had the same radiological distribution as in normal aging or Fahr disease. The first impression was not MELAS because there were no evidence of stroke-like symptoms and radiologic findings; the patient suffered from Parkinson-like symptoms. However, BG calcification is a useful marker for diagnosing mitochondrial disease despite its clinical symptoms, such as BG dysfunction.

Through the report, if there is no stroke episode but deep GM calcification in imaging findings, mitochondrial disease should be suspected according the all clinical features like early onset diabetes, family history and it is emphasized that MELAS blood and genetic tests are necessary.

\section{Acknowledgments}

Funding: This work was supported by the National Research Foundation of Korea (NRF) grant funded by the Government of South Korea (Ministry of Science and ICT, MSIT) (NRF-2020R1C1C1006623).

\section{Footnote}

Conflicts of Interest: Both authors have completed the ICMJE uniform disclosure form (available at https://dx.doi. org/10.21037/qims-21-802). The authors have no conflicts of interest to declare.

Ethical Statement: The authors are accountable for all aspects of the work in ensuring that questions related to the accuracy or integrity of any part of the work are appropriately investigated and resolved. All procedures performed in studies involving human participants were in accordance with the ethical standards of the institutional and/or national research committee(s) and with the Helsinki Declaration (as revised in 2013). Written informed consent was obtained from the patient for publication of this case report and accompanying images. A copy of the written consent is available for review by the editorial office of this journal.
Open Access Statement: This is an Open Access article distributed in accordance with the Creative Commons Attribution-NonCommercial-NoDerivs 4.0 International License (CC BY-NC-ND 4.0), which permits the noncommercial replication and distribution of the article with the strict proviso that no changes or edits are made and the original work is properly cited (including links to both the formal publication through the relevant DOI and the license). See: https://creativecommons.org/licenses/by-nc-nd/4.0/.

\section{References}

1. Younes-Mhenni S, Thobois S, Streichenberger N, Giraud P, Mousson-de-Camaret B, Montelescaut ME, Broussolle E, Chazot G. Mitochondrial encephalomyopathy, lactic acidosis and stroke-like episodes (Melas) associated with a Fahr disease and cerebellar calcifications. Rev Med Interne 2002;23:1027-9.

2. Karicheva OZ, Kolesnikova OA, Schirtz T, Vysokikh MY, Mager-Heckel AM, Lombès A, Boucheham A, Krasheninnikov IA, Martin RP, Entelis N, Tarassov I. Correction of the consequences of mitochondrial 3243A $>$ G mutation in the MT-TL1 gene causing the MELAS syndrome by tRNA import into mitochondria. Nucleic Acids Res 2011;39:8173-86.

3. Seyama K, Suzuki K, Mizuno Y, Yoshida M, Tanaka M, Ozawa T. Mitochondrial encephalomyopathy with lactic acidosis and stroke-like episodes with special reference to the mechanism of cerebral manifestations. Acta Neurol Scand 1989;80:561-8.

4. Sue CM, Crimmins DS, Soo YS, Pamphlett R, Presgrave CM, Kotsimbos N, Jean-Francois MJ, Byrne E, Morris JG. Neuroradiological features of six kindreds with MELAS tRNA(Leu) A2343G point mutation: implications for pathogenesis. J Neurol Neurosurg Psychiatry 1998;65:233-40.

5. Toppet M, Telerman-Toppet N, Szliwowski HB, Vainsel M, Coers C. Oculocraniosomatic neuromuscular disease with hypoparathyroidism. Am J Dis Child 1977;131:437-41.

Cite this article as: Kim HG, Lee KM. Phenotypical heterogeneity of mitochondrial encephalopathy with lactic acidosis and stroke-like episodes in a patient with recurrent movement disorder. Quant Imaging Med Surg 2022;12(3):21622164. doi: 10.21037/qims-21-802 